\title{
Design, Fabrication and Flight Demonstration of a Remotely Controlled Airship for Snow Scientists
}

\author{
Rajkumar Sureshchandra Pant ${ }^{1}$
}

\begin{abstract}
A remotely controlled airship was designed, fabricated and demonstrated within a tight timespan of under a month after receiving the go-ahead. The main design requirement for this airship was to be able to operate from a Helipad located at an altitude of 6,572 feet AMSL under ISA+2O deg.C. The images of the terrain below were recorded during the flight and transmitted in real-time to a ground based system using an onboard telemetry system. The paper describes the methodology followed for sizing of the envelope and key components of the airship, and the procedure followed for in-house fabrication and testing. The major issues that cropped up during the operation of the airship in harsh weather conditions of rain and mild snow, as well as at night, are also highlighted. The demonstration established the efficacy of remotely controlled airships for aerial photography and data collection by snow scientists.
\end{abstract}

KEYWORDS: Lighter-Than-Air systems, Airships, Blimps.

\section{INTRODUCTION}

Aerial surveillance usually requires monitoring the activities of people and/events over a designated area and long period of time from an airborne platform. A monitoring process such as this would essentially be based on steady visuals from the area of interest. The design features and attributes that an aerial surveillance airborne platform must possess should help accomplish this mission completely and efficiently. For instance, such a system should have the ability to take-off and land vertically or from limited areas, since such airborne platforms may need to operate from remote locations, some of which might lack large flat open areas to get airborne and/or land.

The onboard surveillance equipment suite has to steadily focus on the desired area on the ground, from a particular altitude. The quality of the surveillance is directly related to the level of stability that the platform can offer. Hence the airborne platform must be able to hover at an altitude and stay put without causing serious fluctuations to the dynamic surveillance data collection. The platform should be considerably inert to disturbances like crosswind, gust, wavering of the payload surveillance equipment due to maneuvering and induced vibrations by the platform itself.

The platform should also require minimal expertise for operation, and the cyclic procedure from storage to deployment should be prompt and easy. Another important attribute is low cost of manufacture and operation of the system, not to mention the strict environmental regulations that need to be adhered to in this age of rapid degradation of our planet. Hence an airship is arguably the most suitable and preferred prospect 
for an aerial surveillance system, taking into account all the above mentioned desirable attributes of such a system.

Airships are aerodynamically shaped bodies filled with a "Lighter-Than-Air" (LTA) gas that displaces the ambient air, which results in a net upward force due to buoyancy. This is called static (or buoyant) lift, since it is due to the inherent buoyant force, which is generated even when airship is stationary. In addition, an airship also can generate dynamic lift due to the action of aerodynamic forces acting on it as it moves through the air, just like an airplane. Once airborne, airships can perform much like helicopters, remaining nearly geo-stationary for extended periods of time, albeit with much lesser fuel consumption, and noise and vibration levels. A remotely controlled (RC) airship is perhaps much more suitable than a remotely controlled aircraft for aerial surveillance due its long endurance loiter and lower fuel consumption.

Design, fabrication and flight testing of prototypes of several LTA systems for various scientific applications has been carried out at IIT Bombay since 2002 (Gawale and Pant, 2002). Some recent projects include indoor remotely controlled airships for neural network control hardware implementation (Sangole et al., 2006), aerostats as platforms for low-cost re-locatable wireless communications systems (Gawande et al., 2007), outdoor remotely controlled airships for product promotion (Gawale et al., 2008), aerial river ferry using superheated steam-filled balloons (Banerjee et al., 2008), and aerostats for snow cover evaluation (Bhandari and Raina, 2009). The following sections highlight the design process and fabrication.

\section{DESIGN PROCESS}

An RC airship can broadly be divided into the five main components, viz., Envelope, Stabilizer and Fins (empennage), Gondola, Propulsion system and Remote Control system. The conceptual design and sizing of the airship is based on the methodology developed by Pant (2008), utilizing the aerostatic and aerodynamic analysis described in Cheeseman (1999). This methodology arrives at the baseline specifications of a manned airship with inputs on the user specified performance and operational requirements and has been suitably adapted by Gawale et al. (2008) for the design and sizing of RC airships. The scheme of arriving at baseline specifications of an airship to meet the user-specified operating and performance requirements is shown in Fig. 1.

\section{DESIGN REQUIREMENTS}

The key requirement of the RC airship was the ability to deploy the airship from a Helipad located at an altitude of 6,572 ft. AMSL, while carrying a payload camera that could take high resolution photographs of the terrain below and transmit them in-real time. As we shall observe later, the airship had to operate in very cold weather at a high altitude and the envelope material selection and fabrication process had to conform to such harsh environmental conditions. In addition, the airship specifications included limitations on its length and volume. As mentioned earlier, adequate stability of the airship during flight would obviously generate clear photographs for surveillance and this requires the airship to be controlled effectively. The stabilizers and fins were also designed keeping this requirement in mind. Of all these, the prime concern was of the propulsion system which needed to operate at altitudes where density of the air is lower than at sea level. Table 1 lists some of these key design requirements for the airship.

Table 1. Airship design requirements.

\begin{tabular}{|l|c|}
\hline Parameters & Value \\
\hline Payload & $3 \mathrm{~kg}$ \\
\hline Operating altitude & $200 \mathrm{ft} \mathrm{AGL}$ \\
\hline Base station altitude & $6,572 \mathrm{ft} \mathrm{AMSL}$ \\
\hline Design wind speed & $15 \mathrm{~m} / \mathrm{s}$ \\
\hline Off Standard temperature & $20^{\circ} \mathrm{C}$ \\
\hline Operational time & 15 days \\
\hline
\end{tabular}

Apart from the above mentioned requirements, which describe a more involved design process, more often than not we also have the constraint on lowering the cost of manufacturing and operation to a level acceptable to user.

The following sections briefly explain the design of the important components of the RC airship.

\section{ENVELOPE DESIGN}

The envelope is the most crucial component of the airship and its design demands to optimally integrate the aspects of aerodynamics, stability and payload. Based on the constraints of length and payload, the GNVR shape was chosen for the envelope profile. The GNVR shape shown in Fig. 2 consists of three standard 


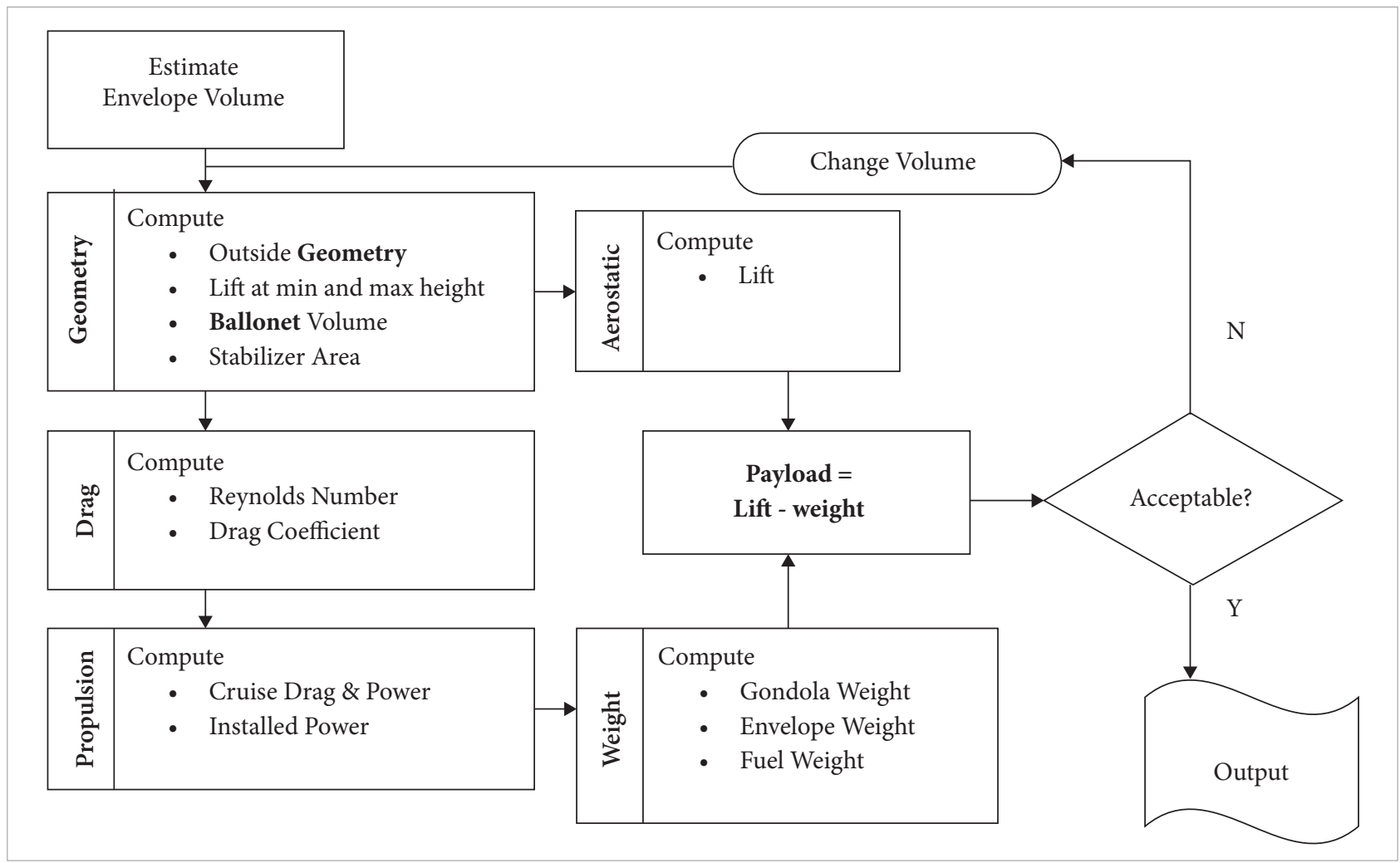

Figure 1. Scheme for determination of baseline specifications of an airship.

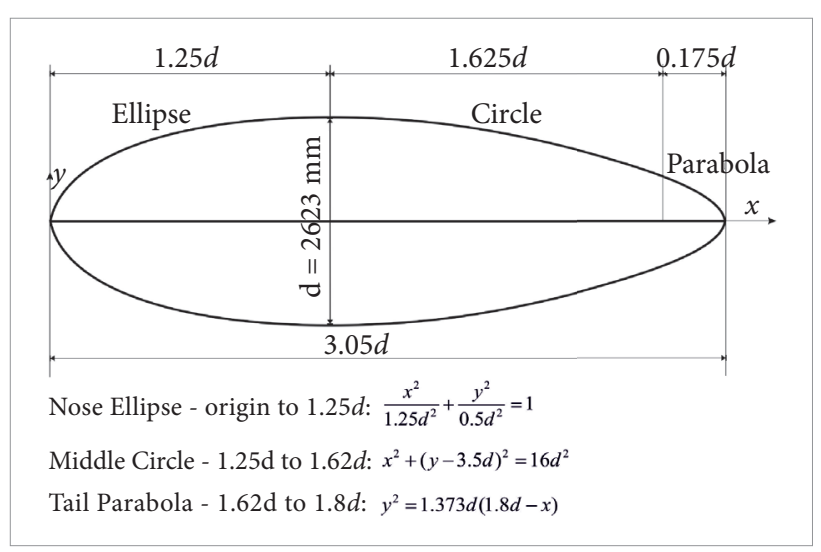

Figure 2. Geometrical Construct of GNVR profile.

sections, and its entire geometry is analytically parameterized in terms of its max diameter $d$. The length and volume of the airship GNVR envelope shape are $8 \mathrm{~m}$ and $26.64 \mathrm{~m}^{3}$. Experimental (Narayana and Srilatha, 2000) and numerical (Sundaram, 2000) studies have shown that this shape is very well suited for tethered aerostats operating at an altitude up to $1 \mathrm{~km}$.

To optimize the fabric thickness, the total load acting on the envelope was calculated as the summation of circumferential and longitudinal loads respectively as given by the equation:

$$
L_{\text {tot }}=P_{\text {int }} \cdot r \pm \frac{M}{\pi r^{2}}
$$

where $M$ is the bending moment and $P_{\text {int }}$ is the internal static pressure.

The pressure distribution on the outer envelope surface has been calculated to identify the points with maximum differential pressure. The total differential pressure was estimated using the equation given below:

$P_{\text {tot }}=P_{\text {aero }}+P_{\mathrm{int}}+\rho_{h e} g h-\rho_{\text {air }} g h$

where $P_{\text {aero }}$ is the dynamic pressure, $P_{\text {int }}$ is the internal static pressure and $h$ is the radius of the envelope.

The center of pressure of this section is located at 33\% of its length, which is also the point at which maximum differential pressure occurs. The flow over the hull is assumed to be turbulent and the drag is estimated in terms of drag coefficient $\mathrm{C}_{\mathrm{DV}}$, maxitmum velocity, volume and the reference area from the formula

$D=\frac{1}{2} C_{D V} \rho V^{2} S$ 
The envelope material has to be appropriately chosen to ensure adequate strength, durability, as well as low weight. A qualitative comparison of the properties of various fabrics that are used for load bearing was carried out and a light weight, yellow coloured PVC fabric was used, keeping in mind the weight, cost and availability constraints. The key properties of this material are listed in Table 2 (Gupta and Malik, 2002).

Table 2. Properties of envelope material used for airship.

\begin{tabular}{|l|c|}
\hline Property & Value \\
\hline $\mathrm{H}_{2}$ permeability @ $25 \mathrm{~cm} \mathrm{H} \mathrm{H}_{2} \mathrm{O}$ column & 3.75 liters $/ \mathrm{m}^{2} /$ day \\
\hline Break strength along warp direction & $1.68 \mathrm{~kg} / \mathrm{cm}$ \\
\hline Break strength along weft direction & $1.76 \mathrm{~kg} / \mathrm{cm}$ \\
\hline Specific weight & $0.14 \mathrm{~kg} / \mathrm{m}^{2}$ \\
\hline Thickness & $0.11 \mathrm{~mm}$ \\
\hline
\end{tabular}

\section{STABILIZER AND RUDDER}

The stabilizer and rudder have been designed to have a cruciform shape on the envelope and the procedure for sizing has been adopted from Gawale and Pant (2002) by scaling down the dimensions of the stabilizer and rudder of existing airships. However, care has been taken to ensure that the scaling is done using data of airships which have envelopes of similar shapes and fineness ratios. A schematic view of the stabilizer for the airship is shown in Fig. 3 and its relevant dimensions are tabulated in Table 3.

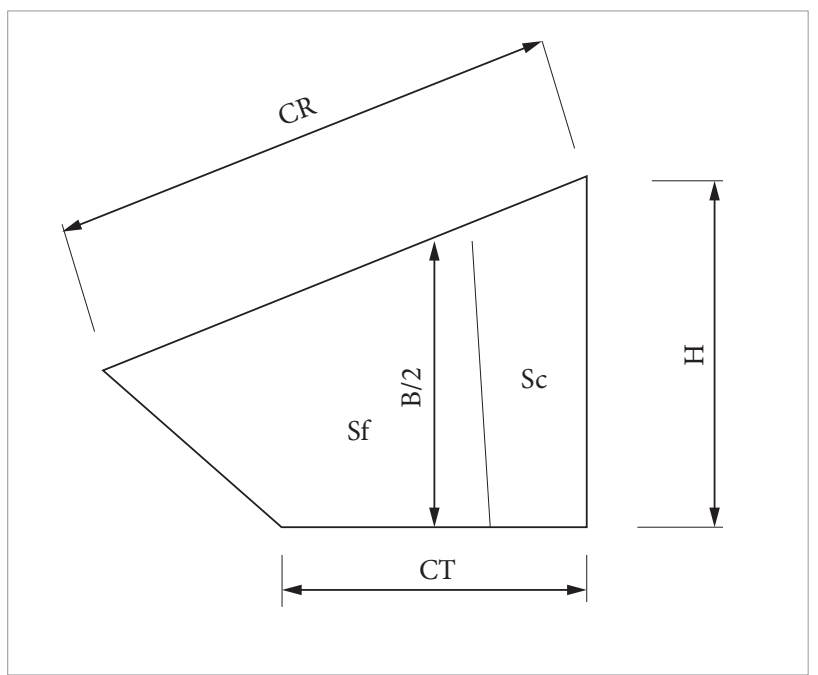

Figure 3. Schematic of the stabilizer \& rudder.

Table 3. Dimensions of the stabilizers.

\begin{tabular}{|l|c|c|}
\hline Parameter & Fixed surface & Moving surface \\
\hline Surface area & $0.61 \mathrm{~m}^{2}\left(\mathrm{~S}_{\mathrm{f}}\right)$ & $0.13 \mathrm{~m}^{2}\left(\mathrm{~S}_{\mathrm{c}}\right)$ \\
\hline$C_{T}$ (tip chord) & $0.86 \mathrm{~m}$ & $0.17 \mathrm{~m}$ \\
\hline$C_{R}$ (root chord) & $1.45 \mathrm{~m}$ & $0.30 \mathrm{~m}$ \\
\hline$H$ (height) & \multicolumn{2}{|c|}{$0.86 \mathrm{~m}$} \\
\hline$B / 2$ (mean half span) & \multicolumn{2}{|c|}{$0.69 \mathrm{~m}$} \\
\hline
\end{tabular}

\section{PROPULSION SYSTEM}

A detailed overview of the power plant system, design issues in engine sizing and selection, advances in engine technology, various concepts for thrust vectoring and a methodology for sizing and selection of design features of an airship engine has been outlined by Gawale and Pant (2004). The specifications of the engine used for this airship have been listed in Table 4 .

Table 4. Specifications of the engine.

\section{Type}

Displacement

Bore

Stroke

RPM

Power output

Mass

\section{STABILITY ANALYSIS}

For a fully stable flight, the center of gravity (CG) of the airship should be exactly at the same location as that of the center of buoyancy (CB). In order to ensure this, a detailed mass breakup and CG analysis was carried out (Table 5). As shown in Table 5, the airship CG and CB were estimated to be located 3.79 and $3.64 \mathrm{~m}$ from the nose, respectively. This small difference in the CG and $\mathrm{CB}$ location helped to create a slightly unstable airship which would be easily maneuverable. 
Table 5. Component mass and center of gravity distribution.

\begin{tabular}{|l|c|c|}
\hline Component & Weight $[\mathrm{kg}]$ & $\begin{array}{c}\text { CG location } \\
\text { from nose } \mathbf{m}]\end{array}$ \\
\hline Envelope & 12.53 & 3.74 \\
\hline Fin velcro strip + hooks & 0.59 & 6.60 \\
\hline Fins & 1.32 & 6.97 \\
\hline Batons & 0.70 & 0.50 \\
\hline Gondola & 3.00 & 3.01 \\
\hline Airship assembly & 18.14 & 3.82 \\
\hline Ballast & 3.37 & 3.64 \\
\hline Total weight & 21.51 & 3.79 \\
\hline
\end{tabular}

\section{FABRICATION}

This section briefly outlines the fabrication methods of the components of the airship.

\section{ENVELOPE}

The envelope is usually constructed by joining smaller sections called petals, as seen in Fig. 4, which are cut out from the fabric sheets using a shape template. The shape template consists of the cross-sectional shape of the envelope generated using the coordinates of the GNVR profile. The envelope petals were then seamed together, as shown in Fig. 5, depending on their orientations using radio frequency (RF) heat welding, thereby forming the whole envelope.

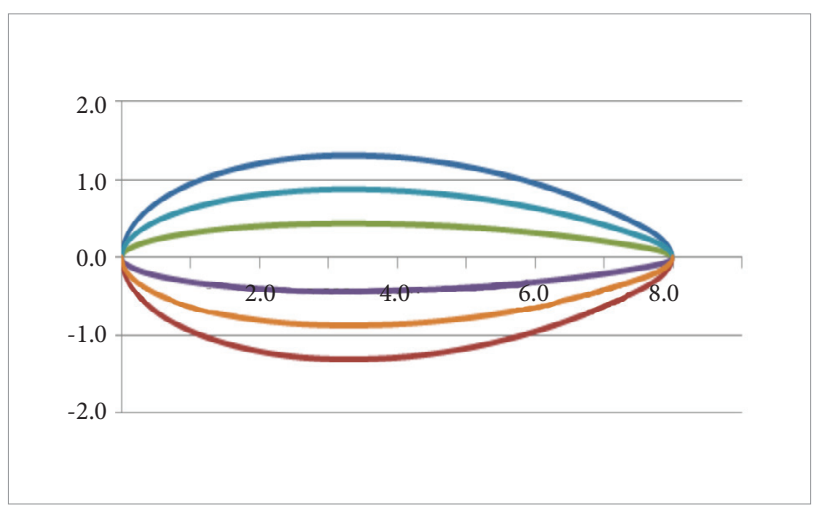

Figure 4. Envelope profile.

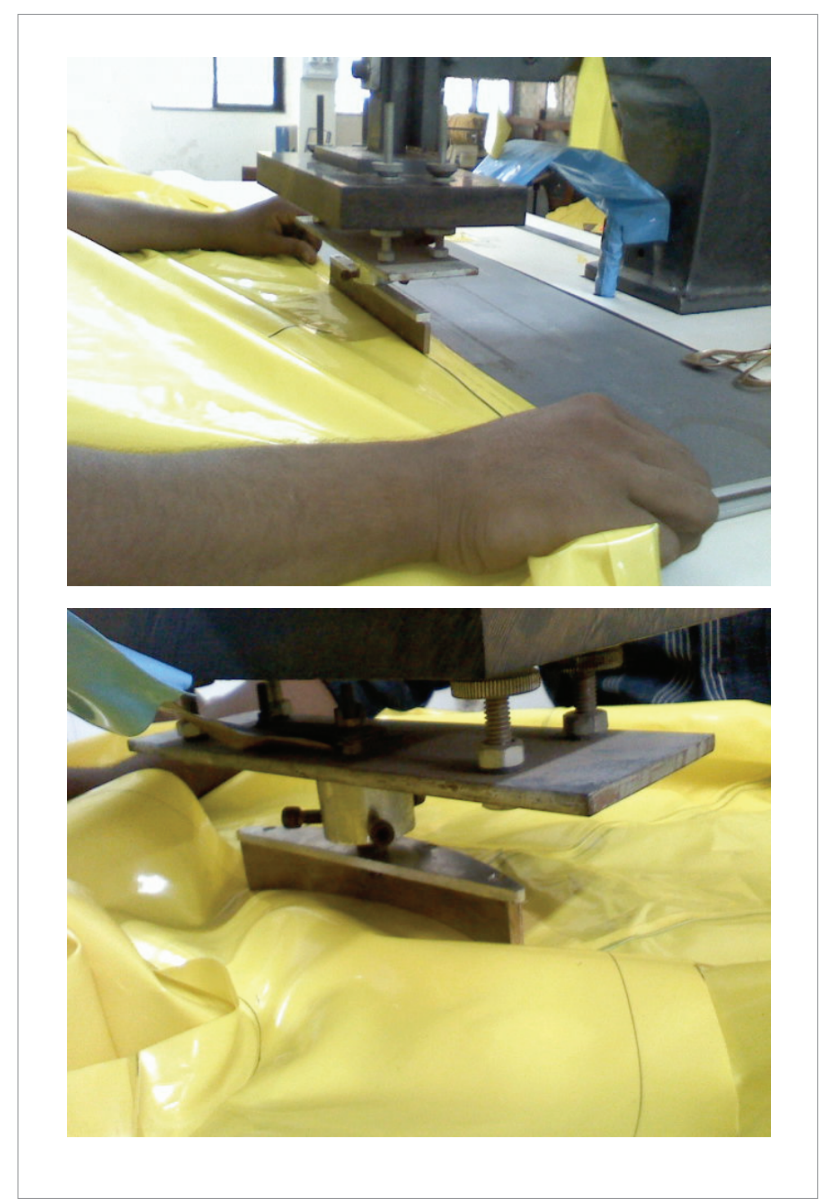

Figure 5. Radio frequency welding of petals.

\section{GONDOLA}

The gondola was sized to accommodate the receiver, battery package, fuel tank, engine and payload. The gondola mounting slots were welded below the envelope and the gondola has been attached directly to the envelope using contoured aluminum rods going into these slots. It was carefully set up upon determining its location and mass, to have as stable an airship as possible.

\section{STABILIZER AND RUDDER}

The fabrication of stabilizer was done using flat sheet of high density foam (expanded polystyrene). Balsa wood was attached at edges to impart stiffness and avoid local damage to the foam due to impact loads. Servo controllers with boosters were fitted to each rudder in such a way that all control surfaces are free to rotate around $30^{\circ}$ about the hinge. In order to attach the stabilizer surfaces, a velcro sheet was pasted on the envelope. A photograph of the ventral stabilizer and rudder is shown in Fig. 6. 


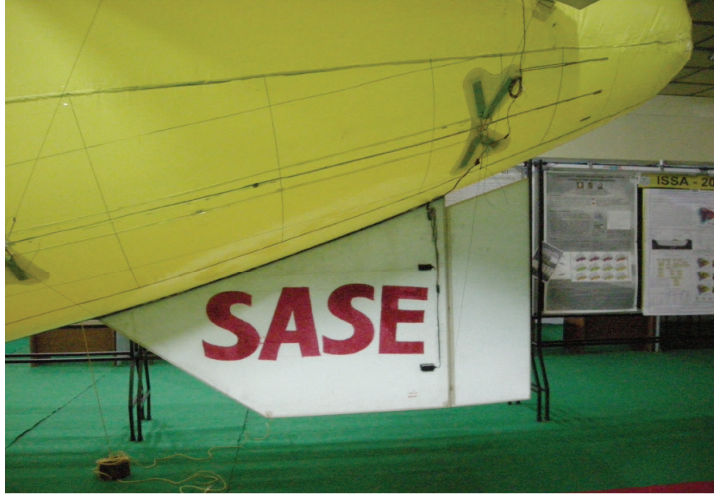

Figure 6. Stabilizer and Rudder.

\section{FLIGHT DEMONSTRATION}

Some of the major concerns dealt before the flight testing was of transportation and leak testing of the envelope. The envelope underwent a leak detection test, where light sources illuminated the holes, if any. Subsequent to the gas leak testing was the complete integration of all the subassemblies and the inflation of the envelope with Helium. The CAD model of the airship along with the fins and a side view of airship are shown adjacently in Fig. 7. It was observed that an additional ballast weight had to be added to the gondola in order to attain stability.

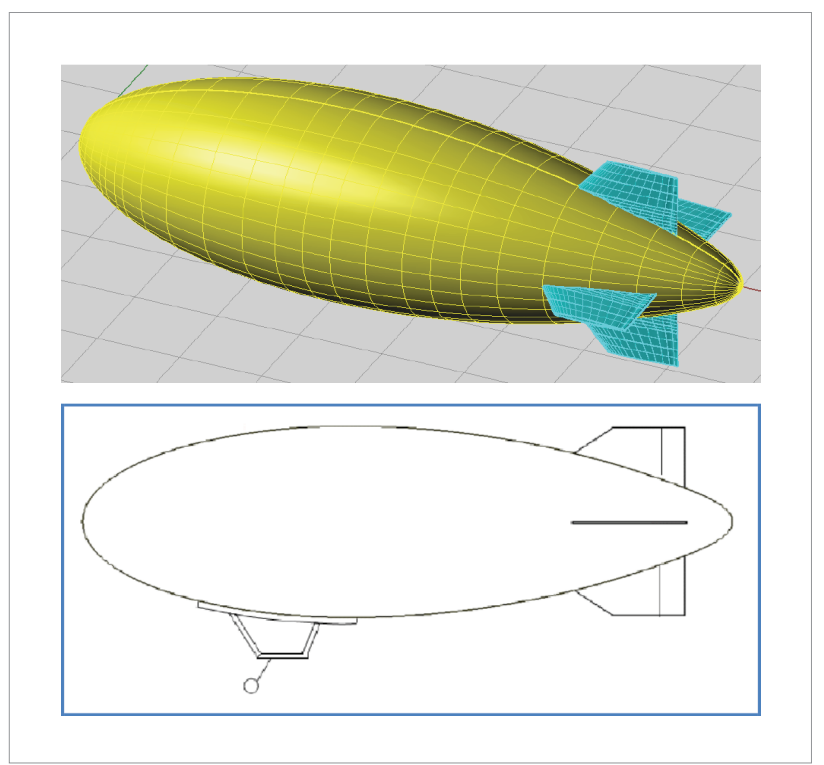

Figure 7. $C A D$ model and airship side view.
The airship was successfully flown during three different weather conditions, viz., dry day, mild rain and mild snowfall. The low density of air at such a high altitude could always resulted in reduced performance of a propeller engine and a small engine set up can amplify this problem. Despite this, the flight performance was quite satisfactory with comfortable take off and climbing flight. The airship was also maneuvered to undergo both level and climbing turning flight, including a touch-down and take-off, which demonstrated its control effectiveness. The completely fabricated airship is shown in Fig. 8. Figure 9 shows some of the images of the airship during its flight.

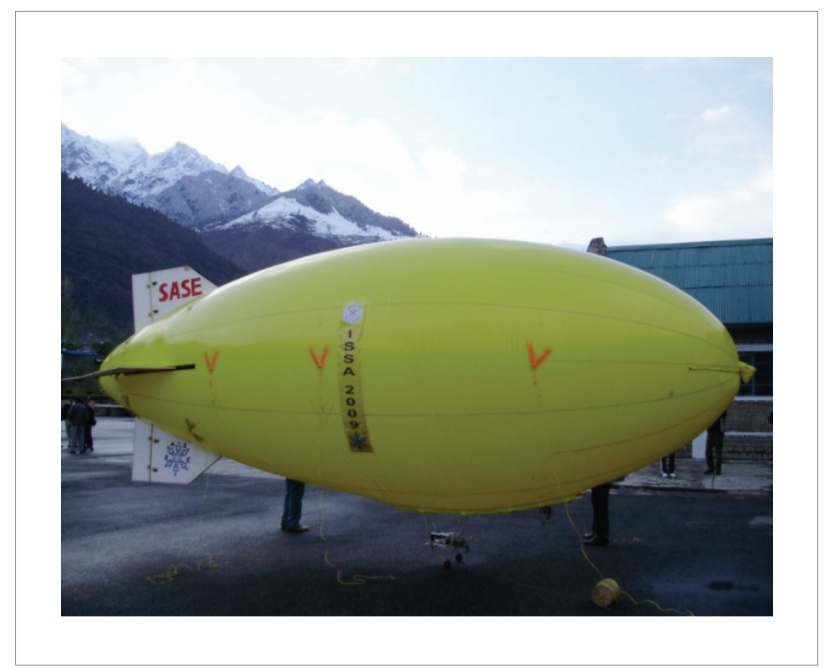

Figure 8. Airship upon complete fabrication.

The airship carried an operating payload which consisted of an autofocus Internet Protocol (IP) camera, which took live footage during its flight. The IP camera was capable of continuously taking photographs at the rate of around one photograph per second and the transmitted sequence of pictures were then combined in a video by playing them at a faster rate. Figure 10 shows the photograph of IP camera mounted on the front of the gondola.

Figure 11 shows two photographs of the aerial footage taken by the onboard IP camera. Figure 12 shows a sequence of four images taken during flight when the LTA gas storage facility (pointed by the red arrow) was being monitored. The onboard camera was capable of procuring clear and crisp images of the people on the ground and layout of the area. 


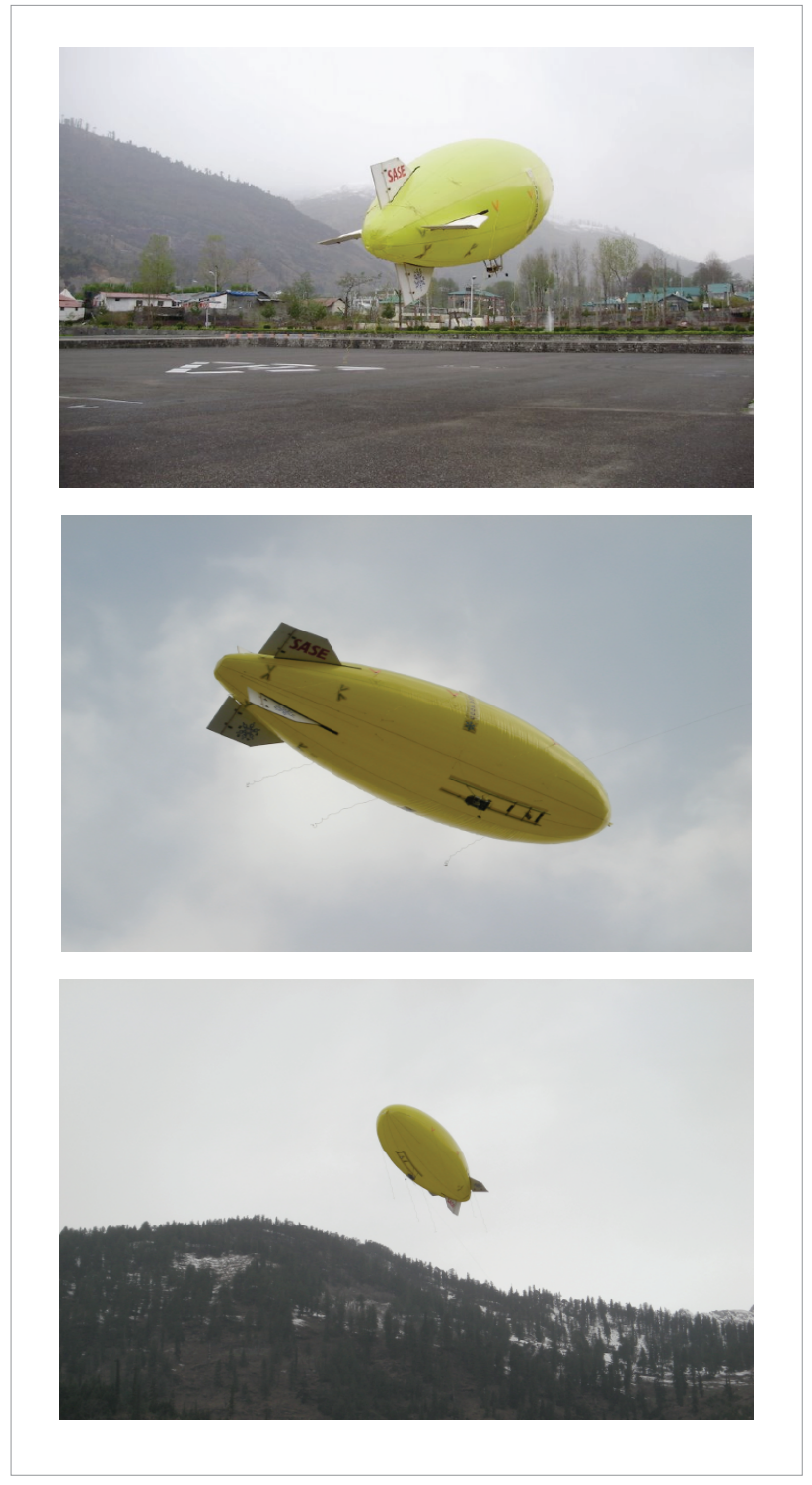

Figure 9. Airship during flight.

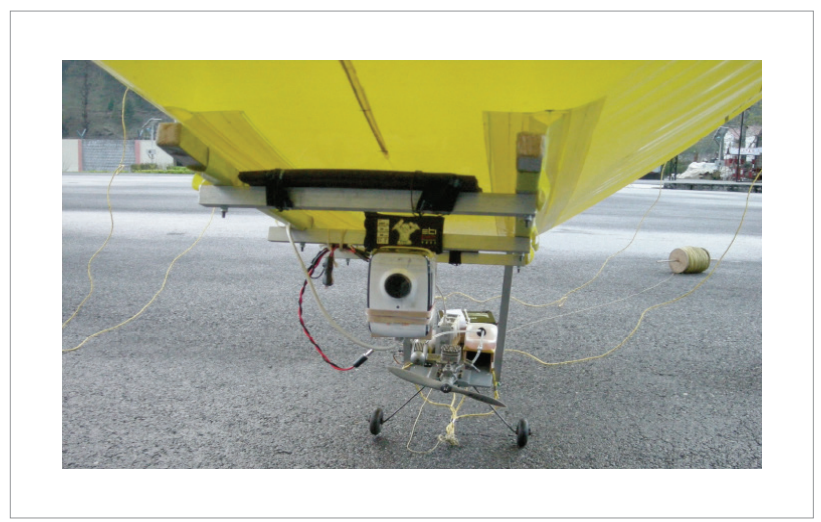

Figure 10. IP camera.

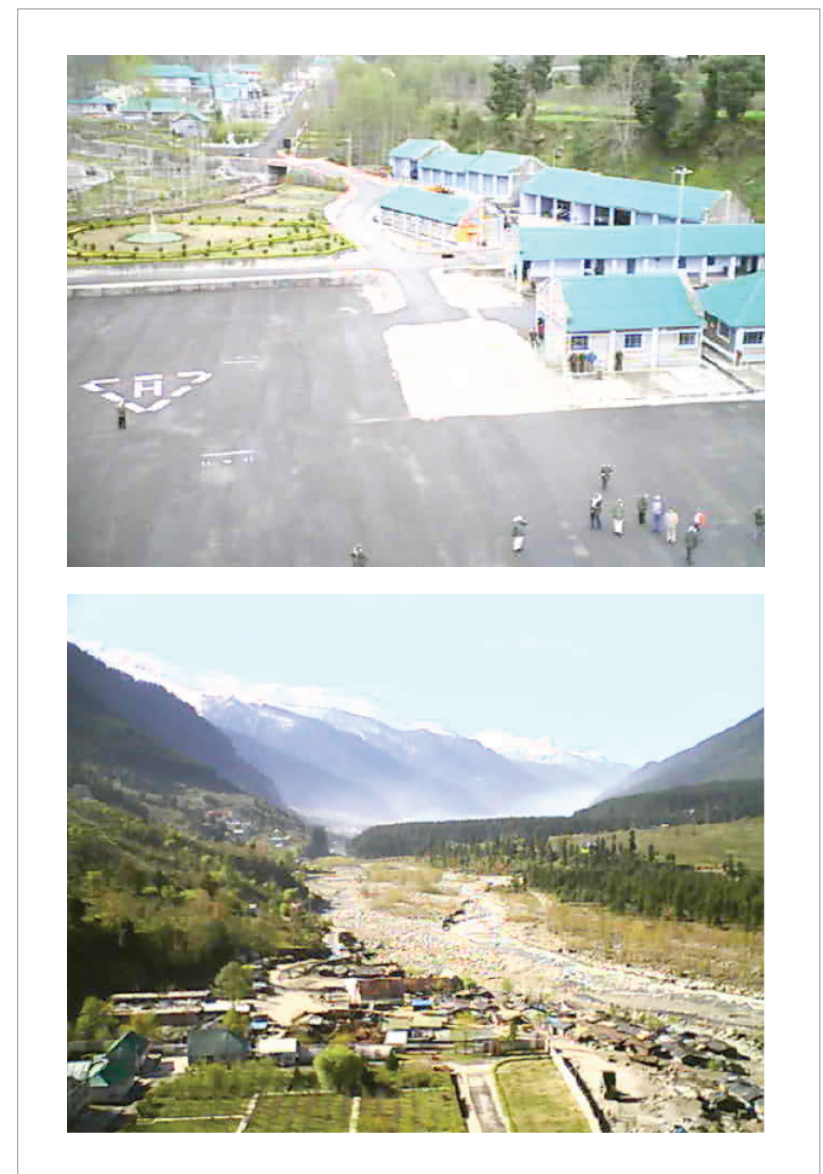

Figure 11. Two aerial photographs taken by onboard IP camera.

\section{CONCLUSIONS}

The design methodology adopted for the design of a RC airship not only covers the basic aspects of airship design but also governs the various options that can be utilized depending on the user's constraints. The fabrication, system integration and operation of the RC airship have stablished the tremendous potential that airships possess to be a highly viable airborne platform for aerial surveillance. The images obtained are steady, clear and can be used to monitor all activities at a given location on the ground. The manufacturing costs and operational issues of such an effective aerial surveillance system have also been found to be much lower than for fixed wing aircraft. The demonstration established the efficacy of remotely controlled airships for aerial photography and data collection by snow scientists. 


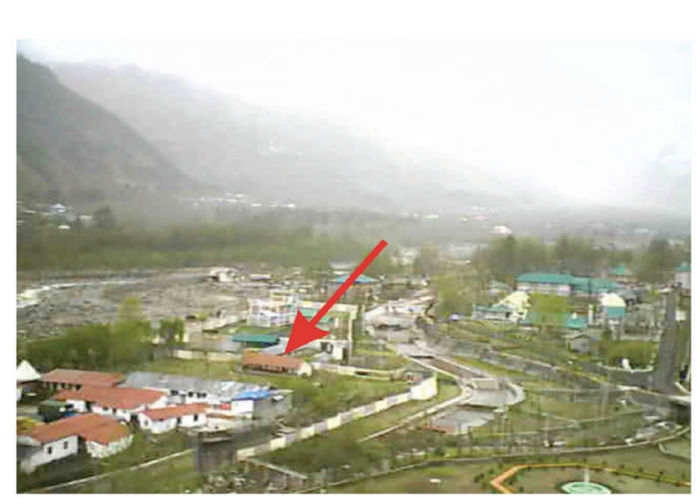

Shot 1

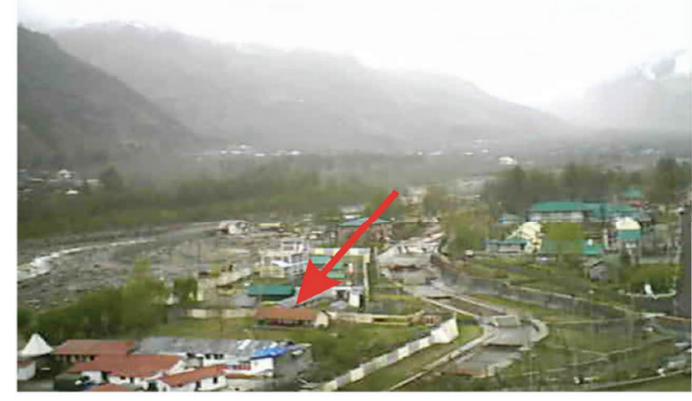

Shot 3

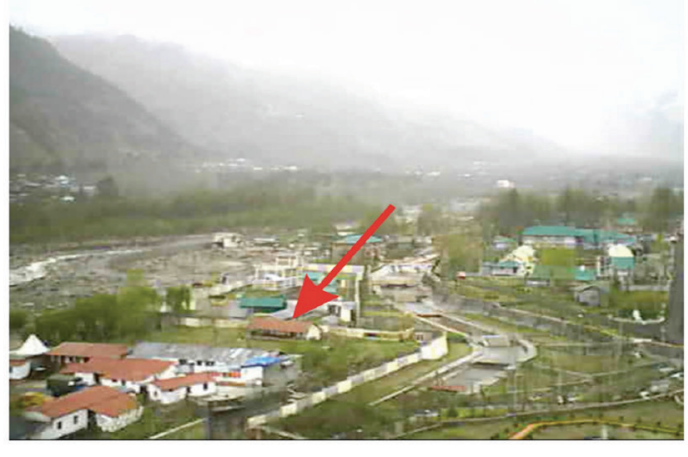

Shot 2

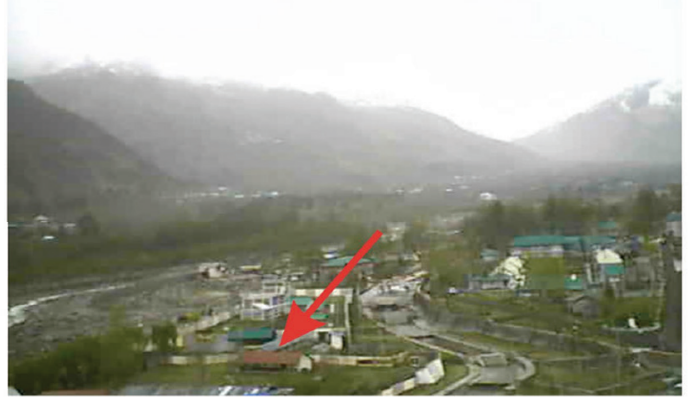

Shot 4

Figure 12. Sequence of photographs taken by the onboard camera.

\section{ACKNOWLEDGMENTS}

The author would like to thank Dr. R. N. Sarwade, Director, and Mr. Jimmy Kansal, Deputy Director of Snow and Avalanches Study Establishment, DRDO, for inviting the team from LTA systems Lab. of IIT Bombay to carry out the demonstration flight of this airship, and express his gratitude towards the following members Mr. Vishal Chaugule, Mr. Kaviresh Bhandari, Mr. Maxwell Rodrigues, Mr. Kushal Moolchandani, Mr. Nilesh Dhanve and Mr. V. D. Patil, who participated in this effort. The help and assistance from Mr. Y. P. Jahagirdar, Director of Research Institute for Model Aeronautics, Ahmednagar, and his team in system integration and flight demonstration is also gratefully acknowledged.

\section{REFERENCES}

Banerjee, S., Raina, A.A. and Pant, R.S., 2008, "Low Cost Transriver Aerial Ferry", Proceedings of AlAA's 8th Aviation Technology Integration and Operations (ATIO) Conference, Anchorage, Alaska, USA, AIAA-2008-8851.

Bhandari, K.M. and Raina A.A., 2009, "Conceptual Design Of A High Altitude Aerostat For Study Of Snow Pattern", Proceedings of International Symposium on Snow \& Avalanches (ISSA-09), SASE, Manali, India.

Cheeseman, I., 1999, "Aerodynamics", In: Khoury, G.A. and Gillet, J.D., Airship Technology, Cambridge Aerospace Series 10, Cambridge University Press, New York, pp. 25-38.

Gawale, A.C. and Pant, R.S., 2002, "Design, Fabrication and Flight Testing of Remotely Controlled Airships", Proceedings of
National Conference on LTA Technologies, Aerial Delivery R\&D Establishment, Agra, India.

Gawale, A. and Pant, R., 2004, "Design Studies of a Powerplant System of Non-Rigid Airship", Proceedings of the 5th International Convention of the Airship Association, Oxford, England.

Gawande, V.N., Raina A.A., Bilaye, P., Pant, R.S. and Desai, U.B., 2007, "Design and Fabrication of an Aerostat for Wireless Communication in Remote Areas", Proceedings of AIAA's 17th Aviation, Technology, Integration, and Operations (ATIO) Conference and 17th Lighter-Than-Air Systems Technology Conference, Belfast, Northern Ireland, UK, AIAA-2007-7832.

Gawale, A., Raina, A.A., Pant, R.S. and Jahagirdar, Y.P., 2008, "Design Fabrication and Operation of Low Cost Remotely Controlled 
Airships in India", Proceedings of AIAA's 18th Aviation Technology Integration and Operations (ATIO) Conference, Anchorage, Alaska, USA, AIAA-2008-8853.

Gupta, S. and Malik, S., 2002, "Envelope Details for Demo Airship", PADD Project Report, Aerial Delivery R\&D Establishment.

Narayana C.L. and Srilatha, K.R., 2000, "Analysis of aerostat configurations by panel methods", BLISS Project Document CF 0010, National Aerospace Laboratories, Bangalore, India.

Pant, R.S., 2008, "Methodology for Determination of Baseline
Specifications of a Non-rigid Airship", Technical Note, AIAA Journal of Aircraft, Vol. 45, No. 6, pp. 2177-2182.

Sangole, R., Agashe, S., Palshikar, K. and Nakanekar, G., 2006, "Design, Fabrication and Testing of Remotely Controlled Indoor Airship employed for Neural Networks Hardware Experimentation", Undergraduate Project Thesis, Mechanical Engineering Department, PVG College of Engineering, University of Pune, India.

Sundaram, S., 2000, "Wind Tunnel tests on 1:7 and 1:28 scale Aerostat Models", Experimental Aerodynamics Divisions, National Aerospace Laboratories, Bangalore, India. 